\title{
Stategic Change Management of the Industrial Enterprise in the Conditions of Digitalization
}

\author{
Galina S. Merzlikina \\ Department of Management and Finance of Production \\ Systems \\ Volgograd State Technical University \\ Volgograd, Russia \\ merzlikina@vstu.ru
}

\author{
Tatyana E. Kozhanova \\ Department of Applied Mathematics \\ Volgograd State Technical University \\ Volgograd, Russia \\ kozhanova.te@yandex.ru
}

\begin{abstract}
Digitalization is usually understood as integration of digital technologies into everyday life by digitalizing everything that can be digitalized. Digitalization in economy creates new opportunities and identifies new challenges for analytics and management. The article claims that the potential of digitalization has not been fully realised yet. It is necessary to improve the methods of database development and data collection and processing. These are the methods of the so-called predictive analytics, which focuses on predicting the future behavior of economic objects and subjects with the aim of making optimal decisions. The authors demonstrate the need for development of new analytical platforms, including those for strategic change management of the industrial enterprise. The article presents a new methodology of drawing up a plan of strategic development of an enterprise. The stage of formation and evaluation of strategic changes and introduction of the general and specific change strategies are "implanted" into the set of stages of strategic plan implementation (the base of this stage is dependence on the speed of an enterprise's response to changes and on willingness to change the segment of an enterprise activity). The authors present the methodological support of strategic change management, which includes the dynamic model (time-adjustable identification, evaluation and visualization of the general and specific strategies), the methodology of strategic change management (gradual identification, evaluation and prediction of results of the activity), and the management efficiency evaluation tools (a set of special economic indicators). For the use of a methodology of strategic change management it was suggested to develop an information matrix - a new analytical platform for strategic change management, used as a base for development of management "holograms" that can help to identify new opportunities for an enterprise development.
\end{abstract}

Keywords: strategic change, digitalization, predictive analytics, dynamic model, management "hologram"

\section{INTRODUCTION}

The aim of the study is to demonstrate the need for development and use of new methodological support (including the development of a new analytical platform) of strategic change management of the industrial enterprise in the conditions of digitalization. To achieve the purpose of the study, the following problems are to be solved: to analyse the potential and the problems of digitalization for strategic change management of the industrial enterprise, to develop the methodological support of strategic change management, and to evaluate the possibility of the use of the suggested methodological support in the conditions of digitalization. Object of the study is a set of economic and industrial entities. Subject of the study is the processes connected with the full digitalization of industrial and economic processes and the set of organisational and administrative relations established as a result of the strategic change management process.

The Strategic Planning Law identifies the need for development of the strategic prognosis for the whole country (Russian Federation) and the importance of the optimal scenario of risk and threat management in the national security issues resolution. For the Strategic Planning Law to be implemented, the current conceptual and regulatory framework on strategic management should be clarified, updated and developed. The article demonstrates the need for development of the set of effective tools based on the use of modern scientific achievements in the sphere of preparation and implementation of optimal socio-economic development scenarios. These tools, as a result, allow to establish the system of interconnected documents on strategic planning [15].

Digital economy can be defined as the economy, the key factor of which is the data presented in digital format [6,7] Digital economy is sustained by the developed information space, and it aims to obtain reliable data on the ongoing processes (economic, financial, and industrial). It is the new data that will be the source of innovative (including intellectual) technologies and the creation (reduction) of value. Nowadays not only the Internet, but also the Neuronet is being discussed: digital neural networks of the economy operate with the big data (capacity, speed, diversity, reliability, viability, value, variability, visualisation); the set of 
socioneuromorphic and self-learning artificial intelligence systems (global databases, enterprise networks, social networks, biometric systems). The opportunities of digitalization imply the collection and analysis of information in the big data systems, the use of new approaches, tools and methods of data processing. This should contribute to the effective decision-making process on the establishment and/or obtaining the competitive position due to costs minimisation (including those in the information search and processing) and the use of new high-performance tools and methodological support.

Change management was suggested by Kurt Lewin in the middle of the 20th century (a three-steps model of the process of change: freezing, changing and refreezing). In 1984 a concept of organisation development was introduced by Howard R. Hughes, Wendell L. French and Cecil H. Bell [8]. In 2006 Jeff Hiatt introduced the ADKAR change model (ADKAR: Awareness, Desire Knowledge, Ability, Reinforcement). Business Process Re-engineering (Michael Hammer \& James Champy) implies "fundamental rethinking and radical redesigning of the company's business processes" that is oriented at fast and visible growth of the most important efficiency indicators, such as costs, quality, speed, etc [9]. Michael Beer and Nitin Nohria introduced Theory $\mathrm{O}$ and Theory E (an authoritarian and a democratic style of change management), which identify evolutionary and revolutionary change models. However, the study of strategic change is not paid enough attention to even in modern publications about management. At the same time, it is the strategic change that in fact defines the strategy of development of an enterprise and its strategic priorities. Any change management (operational or strategic) implies the study of both external and internal environment of the enterprise based on many parameters and a thorough and long observation of changes. Different authors suggest a variety of observation indicators, which makes a comparative analysis of both initial and predictive information more difficult $[10,11]$. Moreover, many indicators "fall out" of the sight of official statistics and demand "field research"; they are quite time-consuming, and therefore they are barely used in practice.

Thus, it is necessary to create new informational-analytical tools for the digital transformation of industries (big data), new business models, and new analytical platforms that allow to solve new analytical challenges for the decision-making process development. The new predictive analytics is to be created. It is the analytics that focuses on the future behaviour of economic entities, but on the deep and broad analysis of the past of both external and internal environment of the enterprise.

To summarise, digitalization creates new opportunities and defines new challenges for analytics and management. It is primarily necessary to improve the methods of databases ("platforms") development, data collection and processing, and predictive analysis.

\section{MATERIALS AND METHOD}

The study used the concepts of the theory of business analysis and management, the theory of industrial economy, the concept of sustainable development, and the theories of accounting and analysis of the enterprise activity, set out in the works of Russian and foreign researchers. The study also implemented the method of statistical observation and analysis, methods, mechanisms, and tools of industrial enterprise management, and the enterprise performance evaluation tools.

Results of the study. It was identified that new opportunities for strategic change management of an industrial enterprise are created in the conditions of digitalization, which allows to form and process big amounts of data. An amount of information and a set of parameters - indicators - depends on the used methodology of strategic change management. Authors presented the methodological support of strategic change management, which includes the method of drawing up a strategic development plan, the method of strategic change management, the matrix of indicators, and the strategic change management "hologram". It is presumed that implementation of methodological support is possible only provided that there will be developed a special analytical platform for strategic change management, which implies analytical observation of a special set of economic indicators and creation of "holograms" of a future economic condition of the enterprise. The use of an analytical platform provides a wide range of opportunities for predictive analytics, necessary for effective decision-making processes.

\section{REVIEW OF THE RESULTS}

\section{A. Digitalization and establishment of analytical platforms in Russian Federation}

It is usually assumed that digitalization (digital communications and interactive innovations) creates the opportunity to work with the data that was previously unavailable or not used due to the difficulty of its processing. Digitalization allows to work with the special analytical tools, big databases (Big Data) (customer profiling, individual development programs - the combination of mass production and responses to individual requests, activization of the customisation processes).

Only by processing the big data it is possible to identify patterns and take them into account in the process of planning, prediction, and management. Industrial Internet of Things (IoT) [12], machine learning, and artificial intelligence create massive databases, but it is also necessary to process this information. Special platforms and methods for data processing are needed for the intellectual equipment and industry management. Markets with network effects (including software markets) are being established that can create new factors of commercial success and contribute to the development of appropriate measures of economic policy, including the anti-monopoly one [13]. Modern digitalization (another one based on another principles, methods, and tools is also possible) is a component of the sixth wave of innovation (distinguished by the convergence of technologies and hybrid technologies); the expected industrial revolution (transition to the industry 4.0) forms a trend towards the growth of knowledge-intensive industries [14]. 
Unfortunately, not all the opportunities of digitalization are used nowadays. Only 5\% of information, collected at the enterprise, is taken into account within the decision-making process. On the other hand, it is the digitalization that allows to "look beyond" and helps to track economic, financial, industrial, and marketing performance, which previously was not only hard to measure, but also impossible to take into account in management. An expending base of information processing methods and new methodological approaches will allow to develop and implement effective management solutions. Previously, an interesting and useful balanced scorecard was not widespread, since a big amount of information and a considerably long period of observation were needed. Existing means of data processing (analogue economy) were not suitable for this potentially useful analytical management tool. However, in the conditions of digitalization its reincarnation might happen.

Implementation of the Program "Digital economy of Russian Federation" includes the following areas: human resources and education, development of research competences and technological reserves, information security, regulatory controls, and information infrastructure. Implementation of the Program will allow to establish new analytical platforms (new approach to collection and presentation of data, formation of unified user information, and creation and use of new analytical indicators with changing information requirements) to obtain operative information on business process management [15-21]. In our country digitalization is currently understood as "the opportunity for equipment provision" (the availability of personal computers, the use of the Internet, digital format of work with clients and suppliers). At the individual level digitalization has achieved certain results, while at the level of organisations it is yet to be improved. Organisations that use: technologies of electronic data interchange - $63.1 \%$, in processing industry $-72.5 \%$; technologies of automatic object identification (RFID) $-5.0 \%$, in processing industry $-10.7 \%$ (2017). Organisations that use special software for meeting organisational, administrative, and economic challenges $52.5 \%$, in processing industry $-66.4 \%$ [16]. Directions in scientific and technological development in Russian Federation are presented by the following two areas: platform technologies and focus areas. Review of statistical information does not allow to see all the opportunities for establishment of new analytical platforms, a unified platform for implementation of strategic planning documents in the area of science and technology, the use of new methods of data processing in industrial and management solutions.

\section{B. Methodological support of strategic change management of the industrial enterprise}

The authors of the article studied the management efficiency evaluation methods on the basis of their purposes, processes, and changes [22-30], developed their own method of drawing up a strategic development plan. The stage of formation and evaluation of strategic changes and introduction of the general and specific change strategies are "implanted" into the set of stages of strategic plan implementation, which are a part of the diagram of an enterprise activity planning.
Stages of strategic plan implementation: 1) the study of external and internal environment of the enterprise; 2) identification of the vision, mission, and aims of the enterprise; 3 ) creation of different varieties of the development strategy; 4) formation and evaluation of strategic changes and introduction of the general and specific change strategies; 5) the choice of a preparatory strategic plan of development; 6) the strategic plan efficiency evaluation based on SWOTanalysis; 7) preparation of a final strategic plan. The authors formed a dynamic model of strategic change management of an industrial enterprise, developed a method of strategic change implementation (Table 1) and a tool management system for implementation of this method (the matrix of economic indicators with reference and valid values) [31,32].

TABLE I. METHOD OF STRATEGIC CHANGE IMPLEMENTATION AT THE ENTERPRISE AND ITS EFFICIENCY EVALUATION

\begin{tabular}{|l|l|}
\hline Stages & \multicolumn{1}{|c|}{ Description } \\
\hline Stage 1 & $\begin{array}{l}\text { Collection of data on the enterprise activity, situation on the } \\
\text { market, and competitors }\end{array}$ \\
\hline Stage 2 & $\begin{array}{l}\text { Enterprise activity evaluation and detection of the presence } \\
\text { or the lack of a general change strategy }\end{array}$ \\
\hline Stage 3 & $\begin{array}{l}\text { Development of a general change strategy and detection of } \\
\text { baseline and target efficiency indicators of its } \\
\text { implementation }\end{array}$ \\
\hline Stage 4 & $\begin{array}{l}\text { Development of measures focused on achieving the aims set } \\
\text { within the general strategy }\end{array}$ \\
\hline Stage 5 & $\begin{array}{l}\text { Implementation of measures focused on achieving the aims } \\
\text { set within the general strategy }\end{array}$ \\
\hline Stage 6 & $\begin{array}{l}\text { Evaluation of implementation of general and specific } \\
\text { strategies of change }\end{array}$ \\
\hline Stage 7 & $\begin{array}{l}\text { Comparative analysis of efficiency indicators of the general } \\
\text { change strategy implementation (analysis of economic } \\
\text { indicators, comparison of reference and valid values) }\end{array}$ \\
\hline Stage 8 & $\begin{array}{l}\text { Preparation of an overview of the results of the general } \\
\text { change strategy implementation }\end{array}$ \\
\hline
\end{tabular}

The set of indicators, assessment criteria, and graphic and numeral presentation of key indicators of profitability, potential, and sustainability of an industrial enterprise allow to have a more comprehensive picture of the following spheres: technology, finance and economics, market, and organisation (for example, business process stability ratio, "customer increment" ratio, risk assessment at the enterprise, controlled risks management, scenario based development ratio, etc.). Within each sphere, the implementation of various specific strategies is possible. Such strategies as reactive, inactive, preactive, and interactive one belong to general strategies. The developed matrix of criteria and indicators, which takes into account specific change strategies used in the main spheres of an industrial enterprise, allows to measure, monitor, and compare indicators with the reference values (the selection of indicators was based on objectivity, availability, statistical observation, and measurability). In fact, the matrix of indicators, which contains achieved, expected, and planned values, forms an analytical platform for change management.

It is presumed that implementation of the suggested methodological support of strategic change management should focus on establishing a special analytical platform for collection and processing of analytical information and for making predictions in form of a graphic (virtual) "hologram" 
of a future condition of the enterprise based on different varieties of expected strategic changes. Fig.1 graphically presents the opportunities for strategic change management.

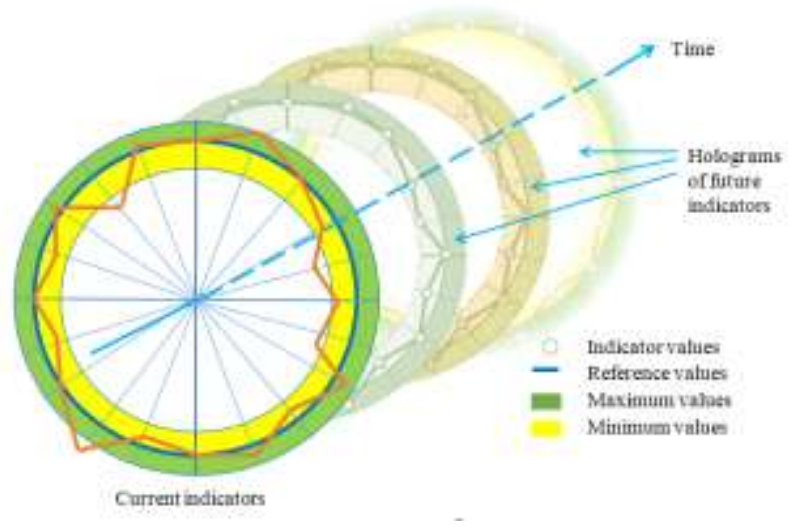

Fig. 1. Strategic change management "hologram" development

The polygon with the information (a basic platform of analytical indicators of four spheres) is a starting point of the "holographing" process. By assigning the new conditions or identifying the known ones it becomes possible to create "holograms" of the future condition of an economic entity (the industrial enterprise), get the integral assessment of this condition, identify the problems of achieving the set goals, and to determine the "pattern of behaviour" - a necessary complex of management solutions.

\section{CONCLUSIONS}

The study identified peculiarities and demonstrated the need for the improvement of strategic change management in the conditions of digitalization. The article also presented methodological support of strategic change management (methodology, "holograms", matrix), the use of which provides some opportunities for analysis and predictive analytics necessary for an effective decision-making process.

The possible problem of establishing an analytical platform is the establishment of an initial, or basic, platform (identification of the algorithms for the calculation of derived indicators). Problems with accessing the information marked as a trade secret can also occur. It is clear, however, that a more thorough analysis of the past and the future of the enterprise, and various methods of forecasting will contribute to making well-informed management decisions, prevent possible threats and risks, and facilitate effective change management.

The study allows to make the following conclusions:

1. The opportunities for and the problems of enterprise management digitalization were analysed, including those of strategic change management.

2. The lack of evaluation of digital support and information on digital support of the enterprise activity was identified (statistically observed indicators rather show the level of tool support). Either the existing analytical platforms should be improved, or the new ones should be established.
3. It is proved that in the conditions of digitalization the initial information for strategic change management (on the example of a suggested methodological support of strategic change management at the enterprise) should be presented in the form of a new analytical platform with its possible further improvement (both methodologically and instrumentally), which creates new opportunities for the development of efficient decision-making processes.

\section{References}

[1] I.D. Matskulyak, N.T. Sapozhnikova, and G.P. Kharchilava, "A breakthrough economy: on the theory of managing changes in economic systems", Manager, vol. 10, no. 4, pp.75-84, 2019.

[2] B.I. Tikhomirov and A.A. Frenkel, "On a Unified Socio-Economic Policy and Strategic Planning”, Economic Policy, no. 4, pp. 82-117, 2017.

[3] N.V. Smorodinskaya and D.D. Katukov, "Distributed production and "smart" agenda of national economic strategies Economic policy", no. 6, pp. 72-101, 2017.

[4] V.K. Krutikov and E.V. Geraeva, "Digital capital and innovative entrepreneurial activity", Economics and Entrepreneurship, no. 3, pp. 703-709, 2018

[5] V.K. Krutikov, Digital economy: problems and opportunities. Kaluga: Publishing house of AKF Politop, pp. 112-141, 2018.

[6] S.A. Dyatlov, "Millennial network human capital as a driver for the development of the digital economy", Izvestia Sankt-Peterburgskogo Gosudarstvennogo universiteta universiteta, no. 4, pp. 26-31, 2019.

[7] T. Phillips, Data Based Management. How to interpret numbers and make quality decisions in business. M.: Mann, Ivanov and Ferber, 140 p., 2017.

[8] Cecil H. Bell and Wendell L. French, Organization development: Behavioral science interventions for organization improvement. 3. ed., Englewood Cliffs (N.J.): Prentice-Hall, Cop., XV, 347 p., 1984.

[9] M. Hammer and J. Champy, Reengineering the Corporation: a Manifesto for Business. Harper Collins Inc., New York, 1993.

[10] M.K. Belyaev and E.V. Prasolova, "Organizational changes: foreign experience and Russian realities", Modern scientific research and innovation, no. 11, part 2, 2014 [Electronic resource]. Available at: http://web.snauka.ru/issues/2014/11/40315 (Accessed: 25.12.2019).

[11] E.I. Dobrolyubova, "Public administration based on results in the era of digital transformation", Issues of state and municipal government, no. 4, 2018.

[12] L.A. Konareva, "Experience in restructuring US and Japanese companies in the 90s", USA, no. 9, pp. 96-106, 2010.

[13] S. Repetyuk, O. Mozgovaya, and B. Fayn, "Regulation of the activities on technological connection of consumers to electric networks: Russian and world experience", Economic Politics, no. 1, pp. 61-78, 2016.

[14] G.F. Yusupova, "FAS vs. Google: Economic Analysis for Specific Markets", Economic Policy, no. 6, pp.82-99, 2016.

[15] S.D. Bodrunov, "Reindustrialization in the context of a new technological revolution: the road to the future", Manager, vol. 10, no. 5, pp. 2-8, 2019.

[16] A.E. Surinov, "Digital Economy: Challenges for Russian Statistics", The Ninth International Scientific and Practical Conference "Modern Economics: Concepts and Models of Economic Development", 2018 [Electronic resource]. Available at: http://d-russia.ru/wpcontent/uploads/2018/07/prezent_27022018. pdf (Accessed: 27.11.2019).

[17] V.A. Kryukov, V.I. Suslov, A.O. Baranov, Yu.S. Blam, A.A. Zabolotsky, N.A. Kravchenko, A.V. Sokolov, N.I. Suslov, G.A. Untura, and V.N. Churashev, "On the content of the draft forecast for the scientific and technological development of the Russian Federation 
[25] S.V. Pogonev and I.Yu. Bocharova, "Theoretical foundations of the industrial enterprise development efficiency", Bulletin of the Voronezh State Technical University, t. 8, no. 10-1, pp. 112-114, 2012.

for the period up to 2030", Problems of forecasting, no. 3, pp. 40-49, 2019.

[18] T. Kostyleva, Ministry of Economic Development published a draft regulation on a digital analytical platform for providing statistical data [Electronic resource]. Available at: http://drussia.ru/minekonomrazvitiya-opublikovalo-proekt-polozheniya-otsifrovoj-analiticheskoj-platforme-predostavleniya-statisticheskihdannh (Accessed: 01.07.2019).

[19] D.Yu. Rozhkova, "Digital platform economy: definition and principles of functioning Management of Economic Systems", 10/201 [Electronic resource]. Available

http://uecs.ru/index.php?option=com_flexicontent $\&$ view=items \& id=4582 (Accessed: 01.10.2019).

[20] V. Mesropyan, Digital platforms - a new market power [Electronic resource]. Available at: https://www.econ.msu.ru/sys/raw.php? $\mathrm{O}=46781 \& \mathrm{p}=$ attachment (accessed date September 3, 2019).

[21] Big data is needed to manage government projects, Analytical Center under the Government of the Russian Federation [Electronic resource]. Available at: http://ac.gov.ru/events/019422.html (Accessed: 27.11.2019).

[22] The official website of the National Research University Higher School of Economics [Electronic resource]. Available at: https://www.hse.ru/news/science/262128924.html/ (Accessed: 12.09.2019).

[23] A.M. Zhemchugov and M.K. Zhemchugov, "Organization goals, end results and performance indicators", Problems of Economics and Management, no. 11, pp. 3-12, 2012.

[24] M.B. Schepakin, "A model for managing the behavior of an economic entity in a changing marketing space", Wschodnioeuropejskie Czasopismo Naukowe, no. 6, pp. 110-116, 2016.
[26] V. Makarova, "How to organize the efficient ERM model in nonfinancial companies and evaluate it efficiency in respect of corporate governance", Journal of Business and Retail Management Research, vol. 11, no. 3, pp. 130-143, 2017.

[27] L.F. Girard, M. Cerreta, and P. De Toro, "Towards a Local Comprehensive Productive Development Strategy: A Methodological Proposal for the Metropolitan City of Naples", Qualuty Innovation Prosperity, no. 21/1, pp. 223-240, 2017. DOI: 10.12776/QIP.V21I1.779.

[28] A.V. Konyashova, "Indicators for assessing the functional components of the economic sustainability of enterprise development", Bulletin of Chelyabinsk State University, no. 8 (299), pp. 123-128, 2013.

[29] Z.B. Atabieva, "Change management in the system of strategic planning of regional development: mechanism, directions, tools", Terra Economicus, vol. 7, no. 4-2, pp. 220-223, 2009.

[30] E.V. Balatsky, "Comparative evolutionary characteristics of foresight technologies”, Science. Innovation Education, no. 5, pp. 65-78, 2008.

[31] E.R. Meteleva, "Strategic management of the development of economic systems in the context of globalization", Bulletin of the Irkutsk State Economic Academy, vol. 26, no. 3, pp. 426-433, 2016.

[32] G.S. Merzlikina and T.E. Kozhanova, "Formation of a change strategy: models, tools and measurement methods", Bulletin of the Belgorod University of Cooperation, Economics and Law, no. 4 (65), pp. 126136, 2017.

[33] G.S. Merzlikina and T.E. Kozhanova, "Effective change management: methodological and instrumental support", Bulletin of the Voronezh state, University of Engineering Technologies, t. 79, no. 2 (72), pp. 248-256, 2017. 